\title{
Physiological and Molecular Characterization of Malassezia pachydermatis Reveals No Differences between Canines and Their Owners
}

\author{
Juan Camilo Galvis Marín1, Fernando Borda Rojas², Andrés Julián Gutiérrez Escobar1 \\ ${ }^{1}$ Group of Biological Investigations and Applied Genetics (GIBGA), Faculty Health Sciences, Universidad de Ciencias Aplicadas y \\ Ambientales (UDCA), Bogotá, Colombia \\ ${ }^{2}$ Animal Science Research Group, Faculty of Animal Sciences, Universidad de Ciencias Aplicadas y Ambientales (UDCA), Bogotá, \\ Colombia \\ Email: jucagama@gmail.com, fborda@udca.edu.co, andresjulian1981@gmail.com
}

How to cite this paper: Marín, J.C.G., Rojas, F.B. and Escobar, A.J.G. (2018) Physiological and Molecular Characterization of Malassezia pachydermatis Reveals No Differences between Canines and Their Owners. Open Journal of Veterinary Medicine, 8, 87-105.

https://doi.org/10.4236/ojvm.2018.87010

Received: April 24, 2018

Accepted: July 28, 2018

Published: July 31, 2018

Copyright $\odot 2018$ by authors and Scientific Research Publishing Inc. This work is licensed under the Creative Commons Attribution International License (CC BY 4.0).

http://creativecommons.org/licenses/by/4.0/

\begin{abstract}
Introduction: The genus Malassezia comprises 17 species of commensal and pathogenic yeasts of homeotherms animal skin. The most common species are M. furfur, M. globosa, and M. sympodialis in humans and M. pachydermatis in animals. However, some publications have reported potentially serious human infections by $M$. pachydermatis in individuals with risk factors and the isolation of human species from domestic animals. Given the scarcity of information about their capacity for transmission between hosts and zoonotic potential, the aim of the present study was to physiologically and molecularly characterize Malassezia spp. isolates obtained from canines and their human owners. Materials and Methods: An experimental study was conducted at the Veterinary Clinic of Universidad de Ciencias Aplicadas y Ambientales of Bogotá (Colombia) from July 2015 to December 2016. Phenotypic identification and molecular characterization via the amplification of the 5.8S rDNAITS2 and 26S rDNA gene regions, nucleic acid sequencing, and phylogenetic analyses were performed on isolates originating from canines with otitis externa and from the skin of healthy owners compatible with Malassezia spp. Results: Eighty samples were cultured, of which 32 (40\%) were suggestive of Malassezia spp. A total of 29 out of $46(63 \%)$ isolates in canines and 3 out of 34 (9\%) isolates in humans corresponded entirely with M. pachydermatis. Isolates from the canines and their owners presented similar behavior in biochemical and phospholipase activity tests, $100 \%$ molecular sequence identities, and close proximity in the phylogenetic trees. Conclusion: The isolation of $M$. pachydermatis from humans and their dogs with identity based on biochemical, physiological, molecular, and phylogenetic perspectives indicate the
\end{abstract}


ability of this species to adapt to new hosts and its potential for zoonotic transmission. These findings contribute to knowledge of the ecology of this important fungus in human and veterinary medicine.

\section{Keywords}

Malassezia, Transmission, Animals, Humans, Zoonosis

\section{Introduction}

The genus Malassezia comprises lipophilic, lipid-dependent, and non-lipiddependent yeasts that are commensal on the skin of humans and animals. These yeasts may become pathogenic in the presence of predisposing factors, such as changes in the cutaneous microenvironment or alterations of host defense mechanisms [1] [2].

The identification of different species within the genus has traditionally been based on phenotypic tests [3]. More recently, identification has depended on molecular biology techniques based on the polymerase chain reaction (PCR) and the sequencing of different genes, such as genes of the ribosomal DNA complex (rDNA), including the 26S and 5.8S subunits [1] [4] [5]. These molecular studies have contributed to our understanding of the biodiversity of the genus and clarified some aspects of its taxonomy and phylogenetic relationships [6] [7] [8], which has led to the determination of new species. Currently, 17 species are recognized [9]-[17].

Species such as $M$. furfur, M. globose, and M. sympodialis are part of the human microbiota and have the ability to produce dermatological syndromes, such as pityriasis versicolor, and to exacerbate diseases, such as seborrheic dermatitis, atopic dermatitis, and psoriasis, as well as systemic syndromes in immunocompromised patients [2] [18]. However, these species have occasionally been reported in domestic animals [19]-[25].

$M$. pachydermatis is the species isolated most often from the skin and mucosa of mammals (mainly canines), in which it can produce otitis externa and dermatitis [26]. However, this species has been reported in potentially serious human infections of individuals with associated risk factors, including some health personnel with contact with dogs [25] [27] [28] [29] [30].

Whether an ecological relationship exists between the presence of this fungus in domestic animals and their owners is not completely clear because few studies have evaluated its capacity for transmission between hosts and the zoonotic potential [31] [32] [33] [34]. Therefore, the objective of the present study was to physiologically and molecularly characterize Malassezia spp. isolates obtained from canines and their human owners.

\section{Materials and Methods}

1) Isolation of Malassezia spp.: 
Skin or external auditory canal swabs were performed on canines with pathologies such as dermatitis or otitis externa and on the skin of healthy owners who attended the Veterinary Clinic of Universidad de Ciencias Aplicadas y Ambientales of Bogota (Colombia) between October 2015 and September 2016. All samples were immediately transported to the microbiology laboratory in a sterile tube containing distilled water and $0.05 \%$ Tween 40 [19] [35] at room temperature. Each sample was inoculated onto modified Dixon agar medium [3] and incubated at $32^{\circ} \mathrm{C}$ for 5 days.

\section{2) Phenotypic identification:}

A smear and Gram staining were performed from the inoculations in which colonies compatible with Malassezia spp. were observed to evaluate the microscopic morphology. Additionally, a new isolation was conducted to obtain pure colonies and to perform phenotypic identification at the species level using the following biochemical tests: urease [36], catalase, $\beta$-glucosidase [37], Cremophor-EL assimilation [38], Tween assimilation, growth on Sabouraud agar [38], 39], and growth on Dixon agar at $37^{\circ} \mathrm{C}$ and $40^{\circ} \mathrm{C}$ [38] [40]. The physiological test for phospholipase activity on Sabouraud agar supplemented with egg yolk was also performed with determination of $\mathrm{Pz}$ index [41].

\section{3) Quality control and maintenance of strains:}

The following reference strains from the Central Bureau voor Schimmelcultures (CBS) were used: $M$. furfur CBS 7019, $M$. pachydermatis CBS 1879, $M$. sympodialis CBS 7222, and M. slooffiae CBS 7956. These strains and the obtained isolates were conserved in skim milk medium at $-20^{\circ} \mathrm{C}$.

\section{4) Extraction of genomic DNA:}

The reference strains and clinical isolates were cultured on modified Dixon agar for 72 hours at $32^{\circ} \mathrm{C}$. Subsequently, DNA extraction was performed using a Fungi/Yeast Genomic DNA Isolation Kit $\left(\right.$ Norgen $\left.^{\circledR}\right)$ according to the manufacturer's instructions. The DNA was stored at $-20^{\circ} \mathrm{C}$ prior to use [42].

\section{5) Amplification of ribosomal genes:}

The primers used to amplify the $5.8 \mathrm{~S}$ rDNA-ITS2 target sequence were ITS3 (5'-GCATCGATGAAGAACGCAGC-3') and ITS4

(5'-TCCTCCGCTTATTGATATGC-3') [39] [43]. The amplification was performed by PCR in a $25-\mu \mathrm{L}$ reaction volume containing $10 \mathrm{X}$ buffer, $2 \mathrm{mM} \mathrm{MgCl}$, $1 \mu \mathrm{mol}$ of each primer, $0.2 \mathrm{mM}$ dNTPs (Thermo Scientific ${ }^{\circledR}$ ), $1 \mathrm{U}$ of Taq polymerase (Bioline ${ }^{\circledR}$ ), and $1 \mu \mathrm{L}$ of genomic DNA under the following conditions: an initial denaturation cycle at $95^{\circ} \mathrm{C}$ for 5 minutes, 25 cycles at $95^{\circ} \mathrm{C}$ for 1 minute, $55.4^{\circ} \mathrm{C}$ for 30 seconds, and $72^{\circ} \mathrm{C}$ for 1 minute, and a final extension cycle at $72^{\circ} \mathrm{C}$ for 5 minutes. The 5'-TAACAAGGATTCCCCTAGTA-3' and 5'-ATTACGCCAGCATCCTAAG-3' primers were used to amplify the $26 \mathrm{~S}$ rDNA target sequence [4] [39]. The amplification was performed by PCR in a $25-\mu \mathrm{L}$ reaction volume containing $10 \mathrm{X}$ buffer, $1.5 \mathrm{mM} \mathrm{MgCl}_{2}, 1 \mu \mathrm{mol}$ of each primer, $0.2 \mathrm{mM}$ dNTPs (Thermo Scientific ${ }^{\circledR}$ ), $1 \mathrm{U}$ of Taq polymerase (Bioline ${ }^{\circledR}$ ), and $1 \mu \mathrm{L}$ of genomic DNA under the following conditions: an initial denatura- 
tion cycle at $95^{\circ} \mathrm{C}$ for 5 minutes, 25 cycles of $95^{\circ} \mathrm{C}$ for 1 minute, $51.7^{\circ} \mathrm{C}$ for 30 seconds, and $72^{\circ} \mathrm{C}$ for 1 minute, and one final extension cycle at $72^{\circ} \mathrm{C}$ for $5 \mathrm{mi}$ nutes. The amplification products were examined by electrophoresis on $1.5 \%$ agarose gels with $1 \mathrm{X}$ TAE buffer and stained with EZ-Vision ${ }^{\circledR}$.

6) Sequencing and phylogenetic analysis:

The amplification products corresponding to the 5.8S rDNA-ITS2 and 26S rDNA regions were sent to Macrogen ${ }^{\circledR}$, Inc. (Korea) for purification and sequencing. The DNA sequences were edited and assembled manually using Geneious v7.0.6 software (created by Biomatters, available at http://www.geneious.com) and subsequently compared with GenBank sequences using the National Center for Biotechnology Information (NCBI) BLASTn tool for identification at the species level. Each data set was aligned using the MUSCLE v3.8.31 algorithm [44] using default parameters, and conserved blocks were selected using Gblocks v0.91b [45]. Phylogenetic reconstruction from the alignments of the conserved blocks was performed using MEGA v7.0.21 software [46]. First, we determined that the evolutionary models that best explained the alignments were T92+G+I and K2. The maximum likelihood methodology was used for the reconstruction of trees under the selected models, and statistical robustness was achieved with 2000 bootstrap replicates. The trees were edited using the iTOL v3. tool [47].

\section{Results}

A total of 80 samples were collected, including 46 samples of canine origin and 34 of human origin. The average age was 5 years for the canines and 33 years for the humans. A total of $37 \%$ of the canines were females and $63 \%$ were males, whereas $38 \%$ of the humans were females and $62 \%$ were males. The demographic and clinical characteristics of the canines and humans included in the study are shown in Table 1.

Thirty-two positive cultures were obtained for Malassezia spp., of which 29 were of canine origin and 3 were of human origin. Of these isolates, $90.6 \%$ were identified as $M$. pachydermatis by phenotypic tests. The remaining isolates were not conclusive for identification at the species level. The phospholipase activity of the studied isolates was high in $87.5 \%$ of the cases, very high in $6.25 \%$ of the cases, and null in $6.25 \%$ of the cases as shown by $\mathrm{Pz}$ indexes (Table 2).

Amplification of the 5.8S rDNA-ITS2 region was performed for the molecular characterization of the isolates. A band of approximately 500-bp was obtained for all isolates of both canine and human origin, at the same height as the reference strain $M$. pachydermatis CBS 1879 (Figure 1(a)). A band of approximately 550-bp was obtained for the 26S rDNA region for all isolates of both canine and human origin, at the same height as the reference strain $M$. pachydermatis CBS 1879 (Figure 1(b)). Note that the molecular size of the reference strain $M$. furfur CBS 7019 is slightly higher. These findings allowed to suspect the molecular identification of $M$. pachydermatis. 
Table 1. Demographic and clinical characterization of the study population.

\begin{tabular}{|c|c|c|}
\hline & Canines & Humans \\
\hline Cases & $46(57.5 \%)$ & $34(42.5 \%)$ \\
\hline Age (years) & $5.1(0.3-15)$ & $33.4(17-57)$ \\
\hline \multicolumn{3}{|l|}{ Sex } \\
\hline Female & $17(37 \%)$ & $13(38.2 \%)$ \\
\hline Male & $29(63 \%)$ & $21(61.8 \%)$ \\
\hline \multicolumn{3}{|l|}{ Breed } \\
\hline Mixed breed & $13(28.3 \%)$ & - \\
\hline Bulldog & $7(15.2 \%)$ & - \\
\hline Golden retriever & $6(13 \%)$ & - \\
\hline Pitbull & $4(8.7 \%)$ & - \\
\hline Other & $16(34.8 \%)$ & - \\
\hline \multicolumn{3}{|l|}{ Type of ear } \\
\hline Drop & $39(84.8 \%)$ & - \\
\hline Erect & $7(15.2 \%)$ & - \\
\hline \multicolumn{3}{|l|}{ Type of hair } \\
\hline Short & $24(52.2 \%)$ & - \\
\hline Long & $22(47.8 \%)$ & - \\
\hline \multicolumn{3}{|l|}{ Lesion site } \\
\hline Skin & $6(13 \%)$ & $4(11.8 \%)$ \\
\hline Ear & $44(95.6 \%)$ & - \\
\hline None & 0 & $30(88.2 \%)$ \\
\hline \multicolumn{3}{|l|}{ Signs and symptoms } \\
\hline Erythema & $15(32.6 \%)$ & $1(2.9 \%)$ \\
\hline Desquamation & $5(10.9 \%)$ & $2(5.9 \%)$ \\
\hline Excoriations & $3(6.5 \%)$ & 0 \\
\hline Scratching & $12(26.1 \%)$ & $2(5.9 \%)$ \\
\hline Head movements & $8(17.4 \%)$ & - \\
\hline Exudate & $23(50 \%)$ & 0 \\
\hline Fetid odor & $12(26.1 \%)$ & - \\
\hline Pruritus & - & $4(11.8 \%)$ \\
\hline Alterations in cutaneous pigmentation & - & $2(5.9 \%)$ \\
\hline None & $12(26.1 \%)$ & $28(82.3 \%)$ \\
\hline \multicolumn{3}{|l|}{ Previous otitis } \\
\hline Yes & $17(37 \%)$ & - \\
\hline No & $29(63 \%)$ & - \\
\hline \multicolumn{3}{|l|}{ Previous dermatitis } \\
\hline Yes & $10(21.7 \%)$ & $5(14.7 \%)$ \\
\hline No & $36(78.3 \%)$ & $29(85.3 \%)$ \\
\hline \multicolumn{3}{|l|}{ Pathological antecedents } \\
\hline Endocrine & $2(4.3 \%)$ & 0 \\
\hline Dermatological & $1(2.2 \%)$ & $2(5.9 \%)$ \\
\hline Other & $8(17.4 \%)$ & $3(8.8 \%)$ \\
\hline
\end{tabular}




\section{Continued}

\begin{tabular}{lcc}
\hline None & $36(78.3 \%)$ & $29(85.3 \%)$ \\
Previous treatments & & \\
Antimicrobials & $7(15.2 \%)$ & 0 \\
Immunosuppressants & $5(10.9 \%)$ & $1(2.9 \%)$ \\
Other & $11(23.9 \%)$ & $3(8.8 \%)$ \\
None & $33(71.7 \%)$ & $31(91.2 \%)$ \\
\hline
\end{tabular}

Table 2. Results of biochemical tests for phenotypic identification.

\begin{tabular}{|c|c|c|c|c|c|c|c|c|c|c|c|c|c|c|c|c|}
\hline \multirow[t]{2}{*}{ Isolates } & \multirow[t]{2}{*}{ Origin } & \multirow[t]{2}{*}{ Morphology } & \multirow[t]{2}{*}{ SDA } & \multicolumn{4}{|c|}{ TDT } & \multirow[t]{2}{*}{ Cremophor } & \multirow[t]{2}{*}{ Catalase } & \multirow{2}{*}{\multicolumn{2}{|c|}{ e Urease $\beta$-glucosidase }} & \multicolumn{3}{|c|}{$\begin{array}{l}\text { Growth on } \\
\text { Dixon }\end{array}$} & \multirow{2}{*}{$\begin{array}{c}\mathrm{Pz} \\
\text { index }\end{array}$} & \multirow[t]{2}{*}{ Identification } \\
\hline & & & & 20 & 40 & 60 & 80 & & & & & $32^{\circ} \mathrm{C}$ & $37^{\circ} \mathrm{C}$ & $40^{\circ} \mathrm{C}$ & & \\
\hline $\begin{array}{l}\text { pachydermatis } \\
\text { CBS } 1879\end{array}$ & $\mathrm{R}$ & $\mathrm{E}$ & \pm & + & + & + & + & + & + & + & + & + & + & + & 0.76 & - \\
\hline $\begin{array}{l}\text { M. furfur } \\
\text { CBS } 7019\end{array}$ & $\mathrm{R}$ & E & - & + & + & + & + & + & + & + & \pm & + & + & + & 0.69 & - \\
\hline $\begin{array}{l}\text { M. sympodialis } \\
\text { CBS } 7222\end{array}$ & $\mathrm{R}$ & $\mathrm{E}$ & - & \pm & + & + & + & + & + & + & + & + & + & + & 0.60 & - \\
\hline $\begin{array}{l}\text { M. slooffiae } \\
\text { CBS } 7956\end{array}$ & $\mathrm{R}$ & C & - & + & + & + & - & - & + & + & - & + & + & + & 1.00 & - \\
\hline $001 \mathrm{C}$ & $\mathrm{C}$ & $\mathrm{E}$ & + & + & + & + & + & + & \pm & + & - & + & + & + & 1.00 & $\begin{array}{c}M . \\
\text { pachydermatis }\end{array}$ \\
\hline $003 \mathrm{C}$ & $\mathrm{C}$ & $\mathrm{E}$ & \pm & + & + & + & + & + & \pm & + & - & + & + & + & 0.71 & $\begin{array}{c}M . \\
\text { pachydermatis }\end{array}$ \\
\hline $003 \mathrm{H}$ & $\mathrm{H}$ & $\mathrm{E}$ & \pm & + & + & + & + & + & \pm & + & - & + & + & + & 0.76 & $\begin{array}{c}M . \\
\text { pachydermatis }\end{array}$ \\
\hline $004 \mathrm{C}$ & $\mathrm{C}$ & $\mathrm{E}$ & + & - & + & + & - & + & \pm & + & - & + & + & \pm & 0.75 & $\begin{array}{c}M . \\
\text { pachydermatis }\end{array}$ \\
\hline $005 \mathrm{C}$ & C & E & \pm & + & + & + & + & + & \pm & \pm & \pm & + & + & + & 0.76 & $\begin{array}{c}M . \\
\text { pachydermatis }\end{array}$ \\
\hline $008 \mathrm{C}$ & C & E & \pm & + & + & + & + & + & \pm & + & + & + & + & \pm & 0.69 & $\begin{array}{c}M . \\
\text { pachydermatis }\end{array}$ \\
\hline 009C & C & $\mathrm{E}$ & + & - & + & + & + & + & \pm & + & + & + & + & + & 0.85 & $\begin{array}{c}M . \\
\text { pachydermatis }\end{array}$ \\
\hline $012 \mathrm{C}$ & C & E & \pm & + & + & + & + & + & \pm & + & + & + & + & + & 0.69 & $\begin{array}{c}M . \\
\text { pachydermatis }\end{array}$ \\
\hline $013 \mathrm{C}$ & C & E & + & - & + & + & + & + & \pm & + & + & + & + & + & 0.79 & $\begin{array}{c}M . \\
\text { pachydermatis }\end{array}$ \\
\hline 015C & C & $\mathrm{E}$ & + & \pm & + & + & + & + & \pm & + & + & + & + & + & 0.69 & $\begin{array}{c}M . \\
\text { pachydermatis }\end{array}$ \\
\hline 016C & C & E & \pm & + & + & + & + & + & \pm & + & + & + & + & \pm & 0.64 & $\begin{array}{c}M . \\
\text { pachydermatis }\end{array}$ \\
\hline 018C & C & $\mathrm{E}$ & + & \pm & + & + & + & \pm & \pm & + & + & + & + & + & 0.77 & $\begin{array}{c}M . \\
\text { pachydermatis }\end{array}$ \\
\hline 019C & C & E & + & + & + & + & + & + & \pm & \pm & + & + & + & + & 0.87 & $\begin{array}{c}M . \\
\text { pachydermatis }\end{array}$ \\
\hline 020C & C & E & + & \pm & + & + & \pm & + & \pm & + & - & + & + & + & 0.85 & $\begin{array}{c}M . \\
\text { pachydermatis }\end{array}$ \\
\hline $021 \mathrm{C}$ & C & E & \pm & + & + & + & + & + & \pm & + & - & + & + & + & 0.86 & $\begin{array}{c}M . \\
\text { pachydermatis }\end{array}$ \\
\hline $022 \mathrm{C}$ & C & E & + & + & + & + & + & + & \pm & + & + & + & + & + & 0.86 & $\begin{array}{c}M . \\
\text { pachydermatis }\end{array}$ \\
\hline
\end{tabular}




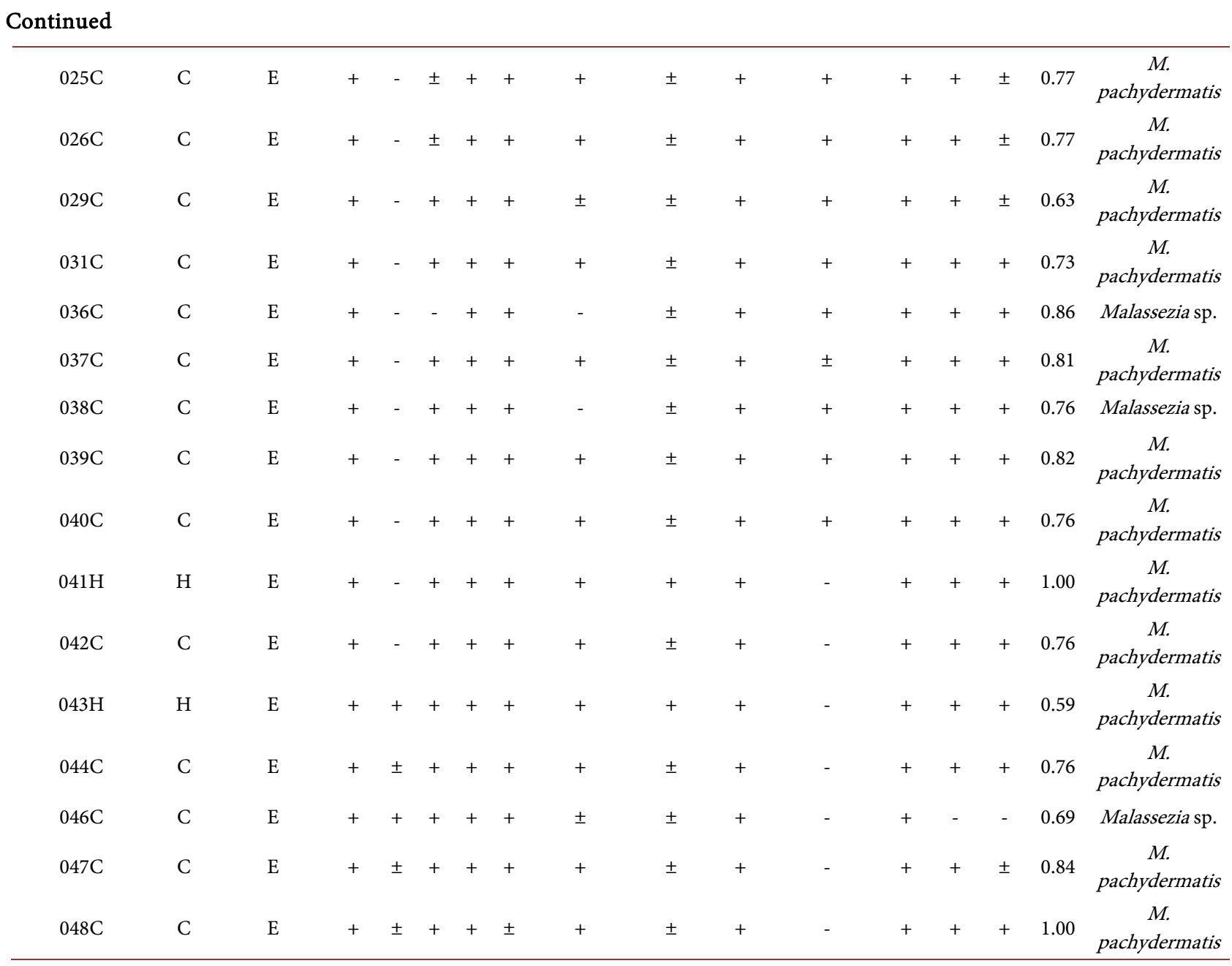

Reference strain (R); canine (C); human (H); ellipsoidal (E); cylindrical (C); Sabouraud dextrose agar (SDA); weakly positive ( \pm ); Tween diffusion test (TDT).

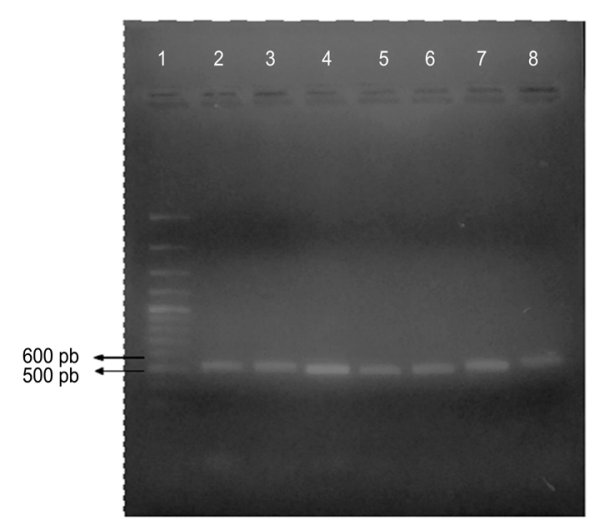

(a)

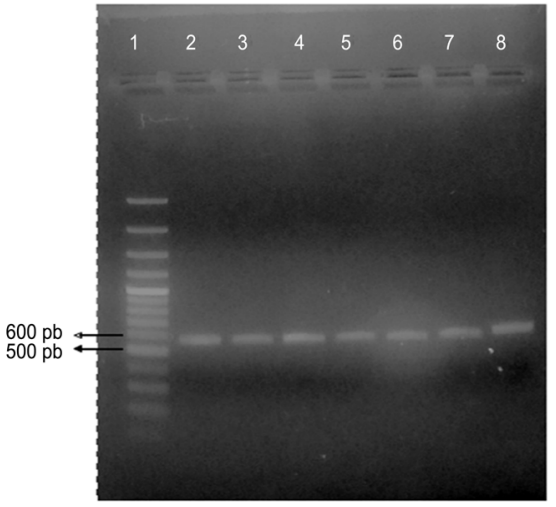

(b)

Figure 1. Amplification of ribosomal genes. (a) Amplification of the 5.8S ADNr-ITS2 region: lane 1, HyperLadder II molecular size marker; lanes 2 - 4, canine isolates; lanes 5 - 6: human isolates; lane 7, M. pachydermatis CBS 1879; lane 8: M. furfur CBS 7019; (b) Amplification of the 26S rDNA region: lane 1, HyperLadder II molecular size marker; lanes 2-4, canine isolates; lanes 5-6: human isolates; lane 7, M. pachydermatis CBS 1879; lane 8: M. furfur CBS 7019. 
However, the consensus sequences of the 5.8S rDNA-ITS2 and $26 \mathrm{~S}$ rDNA regions were obtained, a BLASTn analysis was performed, and these sequences were compared with the sequences deposited in the databases. One hundred percent (100\%) identification of the isolates (i.e., M. pachydermatis) was achieved using the two genetic markers, with identity percentages of $95.6 \%$ $100 \%$ and E-values of 0.0 . Thus, the occurrence of $M$. pachydermatis was confirmed in $63 \%$ of the canines and $9 \%$ of the humans included in the study.

Phylogenetic analyses were performed with the two genetic regions (Figure 2 and Figure 3). All isolates of both canine and human origin clustered together in the same clade with sequences corresponding to $M$. pachydermatis identified with the GenBank accession numbers KY272204 to KY272250 and KU757185 to KU757234 and the reference strain $M$. pachydermatis CBS 1879 . The reference strains of other species of the genus Malassezia and Cryptococcus neoformans CBS 132 were used as outgroups in addition to the sequences of three isolates identified as Cryptococcus spp. In these trees, we can observe the phylogenetic proximity of the isolates of canine and human origin.

Specifically, the $003 \mathrm{H}$ isolate of human origin and the $003 \mathrm{C}$ isolate of the canine owned by this individual showed almost identical biochemical and phospholipase activity profiles (Figure 4), as well as $100 \%$ sequence identity and a close proximity in the phylogenetic reconstructions (Figure 2 and Figure 3 ).

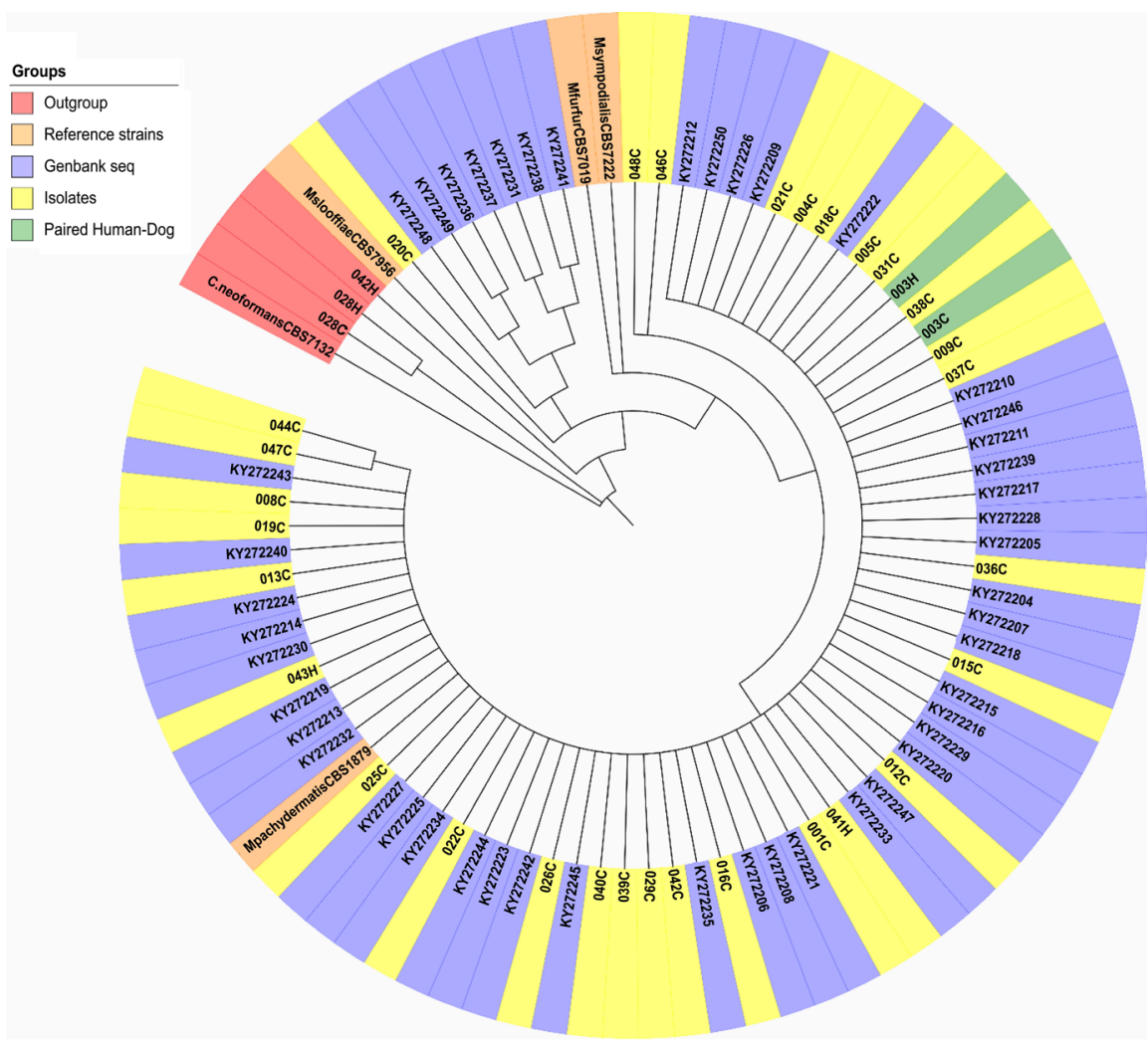

Figure 2. Phylogenetic analysis by maximum likelihood for the 5.8S rDNA-ITS2 region. Human isolates have the letter $\mathrm{H}$ and canine isolates have the letter $\mathrm{C}$. 


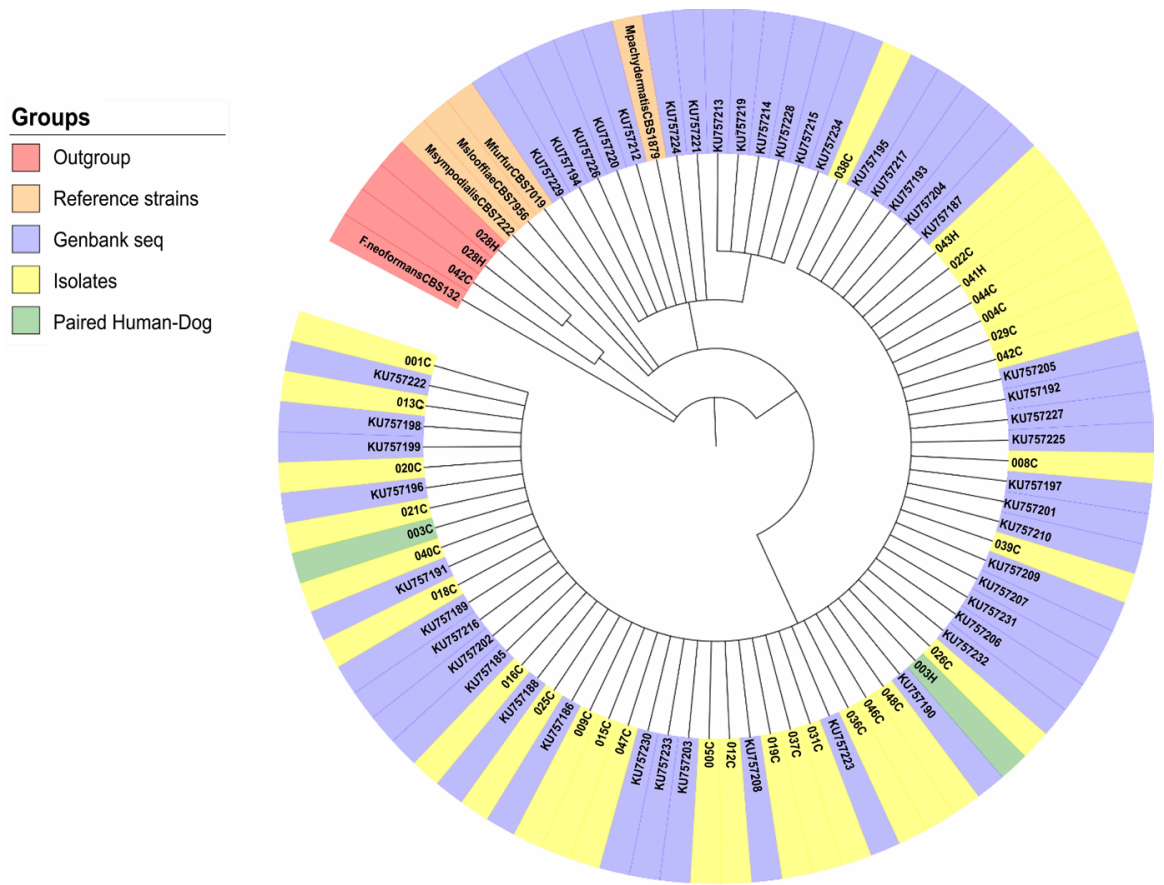

Figure 3. Phylogenetic analysis by maximum likelihood for the $26 \mathrm{~S}$ rDNA region. Human isolates have the letter $\mathrm{H}$ and canine isolates have the letter $\mathrm{C}$.

\section{Discussion}

In the present study, M. pachydermatis was isolated from $63 \%$ of the canine subjects with otitis externa or dermatitis, which coincided with the results reported by several authors who claimed that this yeast was most commonly associated with otic and dermatologic pathologies in canines [19] [20] [23] [48] [49] [50] [51] [52]. M. pachydermatis was isolated from animals of all ages, ranging from 3-month-old puppies to older dogs (15 years). Similar results were found in a Colombian study in which no significant differences were found in the ages of canine patients with otitis caused by Malassezia [19].

When analyzing the canine breeds from which this yeast was isolated, we observed that less than $30 \%$ of the canines corresponded to mixed-breed dogs. This finding agreed with a previous publication that showed that pure breeds were more susceptible to suffering pathologies caused by $M$. pachydermatis [53]. Moreover, the majority of dogs in which the fungus was isolated belonged to breeds with drop ears, which seemed to be a predisposing factor for otitis caused by Malassezia [26]. The main clinical manifestations of the affected canines were scratching, erythema, exudate, and a fetid odor; this description coincides with reports by other researchers [50] [53] and is the result of the inflammatory response triggered by the fungus and associated bacteria, such as Staphylococcus spp. [54].

According to the literature, the canine dermopathies produced by $M$. pachydermatis are generally secondary to other skin conditions, such as allergies, pyoderma, defective keratinization and endocrinopathies [20] [48] [50] [55], or 


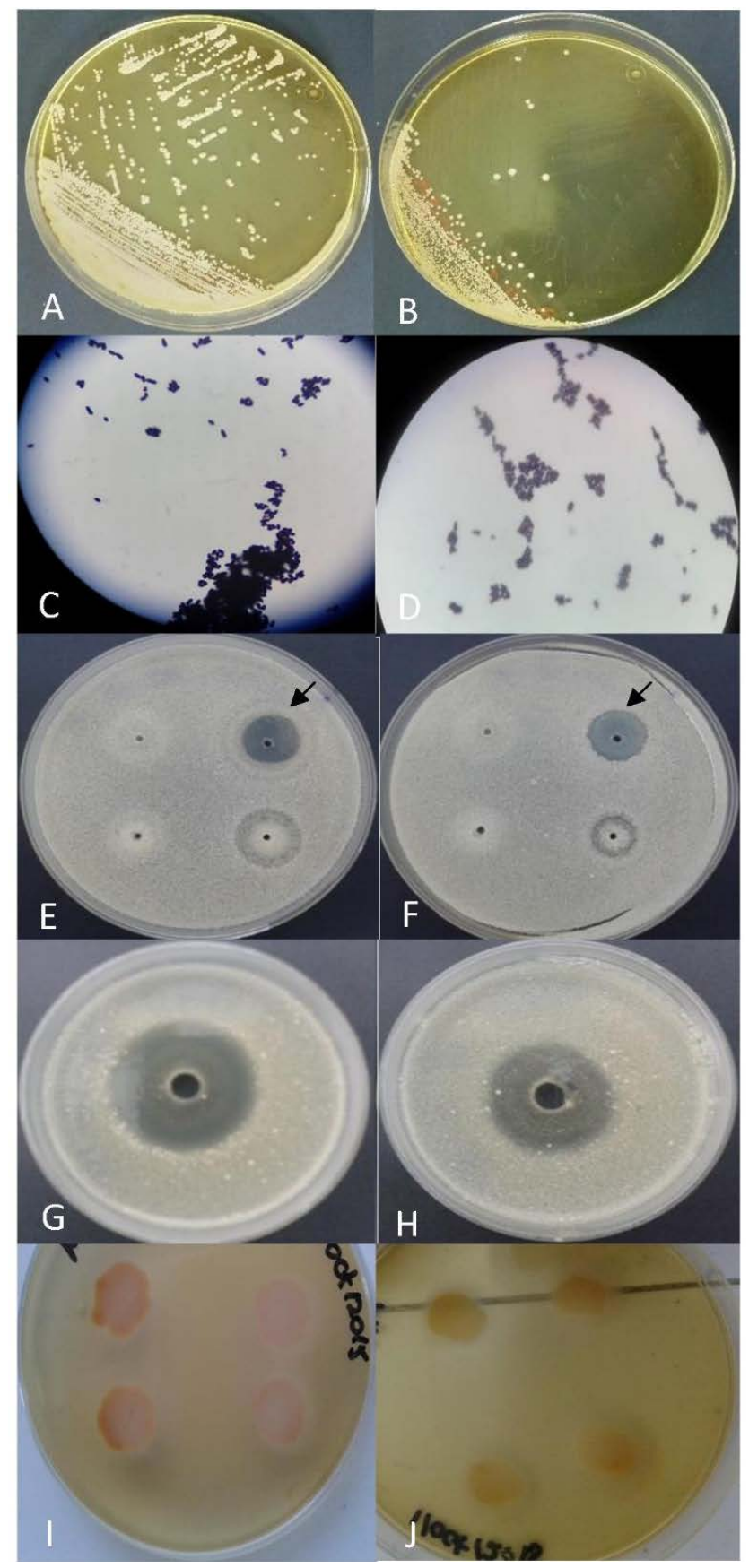

Figure 4. Phenotypic characterization of an isolate of canine origin (column on the left) and an isolate from its owner (column of the right). A and B: Culture on modified Dixon agar in which cream-colored colonies are observed; C and D: Gram staining in which oval levaduriform cells and blastoconidia are observed, 100X; E and F: Diffusion test with Tween 20 (arrow), 40, 60, and 80 (clockwise) in which assimilation of the four lipids can be observed; G and H: Diffusion test with Cremophor-EL (castor oil) in which assimilation of this lipid can be observed; I and J: High phospholipase activity can be observed withPz index of 0.71 and 0.76 , respectively. The results of the enzymatic activity are expressed as a ratio $(\mathrm{Pz})$ which is determined by measuring the diameter of the colony and the diameter of the colony plus the hydrolysis halo that was generated around it. Ranks have been established to classify the phospholipase activity, as follows: $\mathrm{PZ}<0.64$ : very high, $\mathrm{Pz} \geq 0.64$ and $<1$ : high and $\mathrm{Pz}=1$ : null [41]. 
to the use of immunosuppressive and antimicrobial drugs [53]. However, most of the animals that participated in the study did not have a history of dermatitis or other conditions that could favor the growth and pathogenicity of this opportunistic yeast. Therefore, the majority of canines presented a primary dermatomycosis. This observation suggests that there may be companion animals with dermatomycosis, but without underlying diseases. This possibility may facilitate transmission to their owners because the probability of a timely diagnosis and adequate treatment and prevention measures decreases in the absence of significant signs of illness.

M. pachydermatis was isolated from the skin of $9 \%$ of the healthy humans participating in this study. The first publications describing the presence of $M$. pachydermatis on human skin dated back to the 1970s in patients with chronic cutaneous diseases, in which this yeast was isolated in $16 \%$ of the cases [56] and in one patient with a primary immunodeficiency [57]. Later, the isolation of $M$. pachydermatis from skin and other anatomical sites was reported in $47 \%$ of preterm infants and in adults with various syndromes, although whether this yeast actually caused the infections or was a colonizer was unclear [58]. This species was also found in $6 \%$ of healthy patients from cultures of skin smears and conventional biochemical tests, indicating that in most cases, the presence of $M$. pachydermatis on human skin was rare and transient [59].

An additional finding suggesting the exogenous origin of $M$. pachydermatis in human infections is that cutaneous colonization by Malassezia species in healthy full-term infants begins at birth and increases in the first weeks of life for $M$. sympodialis and M. globosa, whereas M. pachydermatis has not been isolated from the skin of newborns or their mothers [60]. In more recent studies, $M$. $p a-$ chydermatis was identified in less than $1 \%$ and up to $5 \%$ of patients with dermatological lesions and healthy controls, respectively, with the isolation of $M$. globosa, M. sympodialis, and M. furfur being more common [30] [35] [61]. However, in the present work, these species were probably not isolated due to their more demanding nutritional requirements.

Using molecular techniques, $M$. pachydermatis was found in only $0.4 \%$ of patients with pityriasis versicolor [62] and in $0.7 \%$ of patients with seborrheic dermatitis [63]. Studies attempting to determine the species of the genus most common in patients with pityriasis versicolor noted that $M$. pachydermatis has only been found in one person with contact with domestic animals [64]. These data support the hypothesis that M. pachydermatis is not a member of the normal human microbiota and that its presence on the skin indicates transmission from an external source, such as contact with companion animals.

No predisposing conditions for infection by this fungus were present in any of the three cases of $M$. pachydermatis isolation in humans apart from contact with canines. The risk factors for $M$. pachydermatis infection have not been well studied. Initially, the most important predisposing factor for systemic $M$. pachydermatis infection was thought to be the same as the case of fungemia by $M$. 
furfur. Infection with this fungus was associated with the lipid-rich parenteral nutrition in immunocompromised patients due to the lipophilicity shared by all species within the genus and their opportunistic behavior because most cases were isolated from the blood and other body fluids of preterm infants in neonatal intensive care units (NICUs) [65]. Thus, M. pachydermatis was found to colonize several anatomical sites in hospitalized patients [66].

The use of molecular biology tests and genetic typing of clinical isolates clearly demonstrated the nosocomial nature of the epidemics caused by $M$. pachydermatis in the NICUs because all isolates recovered from both the patients and the incubator surfaces were genetically comparable and persisted for several months despite regular cleaning [67]. Moreover, identical genetic profiles were generated among strains of $M$. pachydermatis isolated from hospitalized neonates [68]. The data from these studies supported the theory that $M$. pachydermatis could cause outbreaks of nosocomial fungemia and that children with low birth weights, who were severely ill, and who had arterial catheters in place for several days might be at greater risk. Furthermore, nosocomial dissemination from health personnel to patients was thought to be facilitated by inappropriate aseptic and antiseptic techniques of surfaces, and improper hand washing. Thus, meticulous measures of personal hygiene should be implemented for the doctors and nurses who handle newborns, and modifications in cleaning procedures should be implemented [32] [69].

The characterization of isolates of canine and human origin recovered in the present work suggests genetic identity and a possible route of zoonotic transmission. We perform these phenotypic tests because they have been used traditionally in the identification of the species of the genus [1] and to observe if the yeasts recovered from dogs and their owners had similar biochemical and physiological behaviors. The zoonotic association of pets with $M$. pachydermatis infections was speculated in an outbreak described in a NICU whose origin apparently was from the hands of a nurse who had dogs at home. This conclusion was reached by molecular typing because a common strain colonized the dogs, the health worker, and the newborns [32] [70]. The carrier status of $M$. pachydermatis in dog owners was shown from cultures. This species was found in $38.7 \%$ of canine owners with dermatitis or otitis attributed to Malassezia and in only $6 \%$ of healthy dog owners. Conversely, the diagnostic yield of the PCR-based tests was much higher (up to 94\%) [33].

In the literature, the case of a woman with a facial granuloma caused by $M$. pachydermatis was reported; this strain was also found in skin and cerumen scrapings from the dog she owned using microbiological and histopathological techniques [34]. All of the above findings validate the possible zoonotic transmission of $M$. pachydermatis to humans, specifically from close contact with canines. Healthy patients are likely to behave as asymptomatic carriers or reservoirs of the fungus, whereas patients with predisposing factors, either local or systemic, will be at risk for cutaneous or disseminated infection by $M$. pachydermatis. 
In this study, molecular and phylogenetic characterizations of $M$. pachydermatis isolates from humans and canines were performed. Two genetic markers have been described for the systematic analysis of yeasts of the genus Malassezia: the 5.8S rDNA-ITS2 region, which includes the internal transcribed spacers (ITS), whose length differs between species and is usually identical between strains of the same species, and the 26S rDNA region, which includes the D1/D2 domains, whose lengths are identical in all species of the genus and the similarity of the sequences within the same species is greater than $99 \%$ [71]. The amplification of these regions showed similar results to the literature, such as a 483-bp product using the 5.8S rDNA-ITS2 region for M. pachydermatis isolates from the lesions of canines with otitis [43] and a 550-bp product for eight Malassezia species using the $26 \mathrm{~S}$ rDNA region [12]. Sequencing of these products confirmed that all of the isolates corresponded to M. pachydermatis.

Phylogenetic trees constructed with both markers showed the inclusion of isolates of human and canine origin within the same clade. A study in the late twentieth century classified isolates recovered from humans in the sequevar with the most common type sequences of strains isolated from dogs, which suggested the capacity of this canine-specific yeast to adapt to new hosts [31]. Subsequently, the molecular characterization of lipid-dependent isolates from different species of domestic animals was performed. Although that study did not include human strains, four independent clusters as a function of the origin of the yeast were obtained. Thus, whether the value of the genetic differences observed was important for the definition of species or for the process of adaptation to specific hosts was unclear [72].

The observation of genetic variants of $M$. pachydermatis from canine skin and their relationship with corporal distribution and phospholipase activity has also been evaluated. Higher activity is associated with isolates recovered from cutaneous lesions compared to healthy skin, suggesting that the presence of particular genotypes of $M$. pachydermatis on the skin of canines is related to the affinity of the yeast for the host and specific cutaneous sites [73]. In the present work, the relationship between phospholipase activity and anatomical sites was not studied. However, the activity indexes were similar between isolates of canine and human origin, which indicated similar virulence patterns in both host types. The characterization of atypical $M$. furfur isolates from skin lesions of one canine showed the presence of genetic and physiological polymorphisms that could be the result of the adaptation process of this human-specific species to a new host [21]. However, in the present study, the lipid-dependent species specific to humans were not isolated from the canines.

\section{Conclusions}

This study is the first to perform a phenotypic, physiological, molecular, and phylogenetic characterization of $M$. pachydermatis isolates from dogs and their owners. The association between this species and canine otitis externa is well 
known, but few reports of human infections by $M$. pachydermatis are available, and the risk factors have not been well studied. Currently, this yeast is considered rare and transient on human skin and is not part of the normal microbiota, so its isolation suggests an exogenous origin.

Although more robust molecular epidemiology studies are required to confirm the transmission of this canine microorganism to its owners and catalog human infections caused by $M$. pachydermatis as a true emerging zoonosis, finding the yeast in people living with dogs with otitis or dermatitis suggests its capacity to adapt to new hosts. These new hosts will behave as asymptomatic carriers in the case of healthy patients or become ill if they have predisposing factors. All of these findings will contribute to knowledge of the ecology and epidemiology of this fungus of importance in human and veterinary medicine.

\section{Acknowledgements}

The authors thank Universidad de Ciencias Aplicadas y Ambientalesfor financial support of the project and especially the University Veterinary Clinic for their collaboration in the collection of the samples. We also thank the Laboratory of Mycology and Phytopathology at Universidad de Los Andes for kindly providing the reference strains.

\section{Author's Disclosure Statement}

There are no financial interests.

\section{References}

[1] Cafarchia, C., Gasser, R., Figueredo, L., Latrofa, M. and Otranto, D. (2011) Advances in the Identification of Malassezia. Molecular and Cellular Probes, 25, 1-7. https://doi.org/10.1016/j.mcp.2010.12.003

[2] Gaitanis, G., Magiatis, P., Hantschke, M., Bassukas, I. and Velegraki, A. (2012) The Malassezia Genus in Skin and Systemic Diseases. Clinical Microbiology Reviews, 25, 106-141. https://doi.org/10.1128/CMR.00021-11

[3] Guillot, J., Breugnot, C., De Barros, M. and Chermette, R. (1998) Usefulness of Modified Dixon's Medium for Quantitative Culture of Malassezia Species from Canine Skin. Journal of Veterinary Diagnostic Investigation, 10, 384-386. https://doi.org/10.1177/104063879801000418

[4] Mirhendi, H., Makimura, K., Zomorodian, K., Yamada, T., Sugita, T. and Yamaguchi, H. (2005) A Simple PCR-RFLP Method for Identification and Differentiation of 11 Malassezia Species. Journal of Microbiological Methods, 61, 281-284. https://doi.org/10.1016/j.mimet.2004.11.016

[5] Gaitanis, G., Robert, V. and Velegraki, A. (2006) Verifiable Single Nucleotide Polymorphisms of the Internal Transcribed Spacer 2 Region for the Identification of 11 Malassezia Species. Journal of Dermatological Science, 43, 214-217. https://doi.org/10.1016/j.jdermsci.2006.03.013

[6] Guého, E., Kurtzman, C. and Peterson, S. (1989) Evolutionary Affinities of Hetero-Basidiomycetous Yeast Estimated from 18S and 26S Ribosomal RNA Sequence Divergence. Systematic and Applied Microbiology, 12, 230-236. 
https://doi.org/10.1016/S0723-2020(89)80067-0

[7] Begerow, D., Bauer, R. and Boekhout, T. (2000) Phylogenetic Placements of Ustilaginomyceteous Anamorphs as Deduced from LSU rDNA Sequences. Mycological Research, 104, 53-60. https://doi.org/10.1017/S0953756299001161

[8] Fell, J., Boekhout, T., Fonseca, A., Scorzetti, G. and Statzell, A. (2000) Biodiversity and Systematic of Basidiomycetous Yeast as Determined by LSU rDNA D1/D2 Domain Sequence Analysis. International Journal of Systematic and Evolutionary Microbiology, 50, 1351-1371. https://doi.org/10.1099/00207713-50-3-1351

[9] Sugita, T., Takashima, M., Shinoda, T., Suto, H., Unno, T., Tsuboi, R., Ogawa, H. and Nishikawa, A. (2002) New Yeast Species Malassezia dermatis Isolated from Patients with Atopic Dermatitis. Journal of Clinical Microbiology, 40, 1363-1367. https://doi.org/10.1128/JCM.40.4.1363-1367.2002

[10] Sugita, T., Takashima, M., Kodama, M., Tsuboi, R. and Nishikawa, A. (2003) Description of a New Yeast Species Malassezia japonica and Its Detection in Patients with Atopic Dermatitis and Healthy Subjects. Journal of Clinical Microbiology, 41, 4695-4699. https://doi.org/10.1128/JCM.41.10.4695-4699.2003

[11] Gupta, A., Boekhout, T., Theelen, B., Summerbell, R. and Batra, R. (2004) Identification and Typing of Malassezia Species by AFLP and Sequence Analysis of the ITS and LSU Regions of rDNA. Journal of Clinical Microbiology, 42, 4253-4260. https://doi.org/10.1128/JCM.42.9.4253-4260.2004

[12] Hirai, A., Kano, R., Makimura, K., Duarte, E., Hamdan, J., Lachance, M., Yamaguchi, H. and Hasegawa, A. (2004) Malassezia nana, a Novel Lipid-Dependent Yeast Species Isolated from Animals. International Journal of Systematic and Evolutionary Microbiology, 54, 623-627. https://doi.org/10.1099/ijs.0.02776-0

[13] Sugita, T., Tajima, M., Takashima, M., Amaya, M., Saito, M., Tsuboi, R. and Nishikawa, A. (2004) A New Yeast Malassezia yamatoensis Isolated from Patients with Seborrheic Dermatitis and Its Distribution in Patients and Healthy Subjects. Microbiology and Immunology, 48, 579-583. https://doi.org/10.1111/j.1348-0421.2004.tb03554.x

[14] Cabañes, F., Theelen, B., Castellá, G. and Boekhout, T. (2007) Two New Lipid-Dependent Malassezia Species from Domestic Animals. FEMS Yeast Research, 7, 1064-1076. https://doi.org/10.1111/j.1567-1364.2007.00217.x

[15] Cabañes, F., Vega, S. and Castellá, G. (2011) Malassezia cuniculi sp. nov., a Novel Yeast Species Isolated from Rabbit Skin. Medical Mycology, 49, 40-48.

[16] Cabañes, F., Coutinho, S., Puig, L., Bragulat, M. and Castellá, G. (2016) New Lipid-Dependent Malassezia Species from Parrots. Revista Iberoamericana de Micología, 33, 92-99. https://doi.org/10.1016/j.riam.2016.03.003

[17] Honnavar, P., Prasad, G., Ghosh, A., Dogra, S., Handa, S. and Rudramurthy, S. (2016) Malassezia arunalokei sp. nov., a Novel Yeast Species Isolated from Seborrheic Dermatitis Patients and Healthy Individuals from India. Journal of Clinical Microbiology, 54, 1826-1834. https://doi.org/10.1128/JCM.00683-16

[18] Tragiannidis, A., Bisping, G., Koehler, G. and Groll, A. (2009) Malassezia Infections in Immunocompromised Patients. Mycoses, 53, 187-195. https://doi.org/10.1111/j.1439-0507.2009.01814.x

[19] Pulido, A., Castañeda, R., Linares, M. and Mercado, M. (2010) Clinical-Microbiological Diagnostic of External Otitis in Canines in Bogotá, Colombia. Revista MVZ Córdoba, 15, 2215-2222. https://doi.org/10.21897/rmvz.308

[20] Yurayart, C., Chindamporn, A., Suradhat, S., Tummaruk, P., Kajiwara, S. and Pra- 
pasarakul, N. (2011) Comparative Analysis of the Frequency, Distribution and Population Sizes of Yeasts Associated with Canine Seborrheic Dermatitis and Healthy Skin. Veterinary Microbiology, 148, 356-362.

https://doi.org/10.1016/j.vetmic.2010.09.020

[21] Cafarchia, C., Latrofa, M., Figueredo, L., Da Silva, M., Ferreiro, L., Guillot, J., Boekhout, T. and Otranto, D. (2011) Physiological and Molecular Characterization of Atypical Lipid-Dependent Malassezia Yeasts from a Dog with Skin Lesions: Adaptation to a New Host? Medical Mycology, 49, 365-374.

[22] Brigitta, B., Edina, B., Nocoletta, S. and Gyory, H. (2014) Isolation of Malassezia furfur from Canine Skin Scrapings. Magyar Allatorvosok Lapja, 136, 41-44.

[23] Pulido, A., Castañeda, R., Linares, M. and Mercado, M. (2015) Concordance between Otic Cytology and Culture in Diagnosis of External Otitis Canine by Malassezia spp. Revista MVZ Córdoba, 20, 4720-4724. https://doi.org/10.21897/rmvz.42

[24] Shokri, H. and Khosravi, A. (2016) An Epidemiological Study of Animals Dermatomycosis in Iran. Journal de Mycologie Médicale, 2, 170-177. https://doi.org/10.1016/j.mycmed.2016.04.007

[25] Galvis, J. and Borda, F. (2016) Infecciones zoonóticas por levaduras del género Malassezia: Una revisión. Revista U.D.C.A Actualidad \& Divulgación Científica, 19, 381-393.

[26] Bond, R., Guillot, J. and Cabañes, F. (2010) Malassezia Yeasts in Animal Disease. In: Boekhout, T., Guého, E., Mayser, P. and Velegraki, A., Ed., Malassezia and the Skin, Springer-Verlag, Berlin, 271-299. https://doi.org/10.1007/978-3-642-03616-3_10

[27] Guillot, J. and Bond, R. (1999) Malassezia pachydermatis. A Review. Medical Mycology, 37, 295-306. https://doi.org/10.1046/j.1365-280X.1999.00237.x

[28] Chitty, J. and Hendricks, A. (2007) Zoonotic Skin Disease in Small Animals. In Practice, 29, 92-97. https://doi.org/10.1136/inpract.29.2.92

[29] Mani, I. and Maguire, J. (2009) Small Animal Zoonoses and Immunocompromised Pet Owners. Topics in Companion Animal Medicine, 24, 164-174. https://doi.org/10.1053/j.tcam.2009.07.002

[30] Prohic, A., Jovovic, T., Krupalija, M. and Kuskunovic, S. (2016) Malassezia Species in Healthy Skin and in Dermatological Conditions. International Journal of Dermatology, 55, 494-504. https://doi.org/10.1111/ijd.13116

[31] Guillot, J., Guého, E., Chévrier, G. and Chermette, R. (1997) Epidemiological Analysis of Malassezia pachydermatis Isolates by Partial Sequencing of the Large Subunit Ribosomal RNA. Research in Veterinary Science, 62, 22-25. https://doi.org/10.1016/S0034-5288(97)90174-0

[32] Chang, H., Miller, H., Watkins, N., Arduino, M., Ashford, D., Midgley, G., Agüero, S., Pinto, R., von Reyn, C., Edwards, W., McNeil, M. and Jarvis, W. (1998) An Epidemic of Malassezia pachydermatis in an Intensive Care Nursery Associated with Colonization of Health Care Workers' Pet Dogs. The New England Journal of Medicine, 338, 706-711. https://doi.org/10.1056/NEJM199803123381102

[33] Morris, D., O’Shea, K., Shofer, F. and Rankin, S. (2005) Malassezia pachydermatis Carriage in Dog Owners. Emerging Infectious Disease, 11, 83-88. https://doi.org/10.3201/eid1101.040882

[34] Fan, Y., Huang, W., Li, S., Wu, G., Lai, K. and Chen, R. (2006) Granulomatous Skin Infection Caused by Malassezia pachydermatis in a Dog Owner. Archives of Dermatology, 142, 1181-1184. https://doi.org/10.1001/archderm.142.9.1181

[35] Rincón, S., Celis, A., Sopó, L., Motta, A. and Cepero, M. (2005) Malassezia Yeast 
Species Isolated from Patients with Dermatologic Lesions. Biomédica, 25, 189-195. https://doi.org/10.7705/biomedica.v25i2.1341

[36] Pérez, C., Goitia, K., Mata, S., Hartung, C., Colella, M., Reyes, H., Hernández, C., Villarroel, M., Ontiveros, J., Magaldy, S. and Suárez, R. (2002) Use of the Stuart Urea Broth for the Urease Test: Like Proof in the Identification of Yeast. Revista de la Sociedad Venezolana de Microbiología, 22, 77-80. https://doi.org/10.1007/BF00399623

[37] Khosravi, A., Eidi, S., Ziglari, T. and Bayat, M. (2008) Isolation and Differentiation of Malassezia Species Isolated from Healthy and Affected Small Animals, Ear and Skin. World Journal of Zoology, 3, 77-80.

[38] Kaneko, T., Makimura, K., Abe, M., Shiota, R., Nakamura, Y., Kano, R., Hasegawa, A., Sugita, T., Shibuya, S., Watanabe, S., Yamaguchi, H., Abe, S. and Okamura, N. (2007) Revised Culture-Based System for Identification of Malassezia Species. Dournal of Clinical Microbiology, 45, 3737-3742.

[39] Hernández, J. (2005) Caracterización molecular de especies del género Malassezia. Ph.D. Dissertation, Universidad Autónoma de Barcelona, Barcelona, España.

[40] Guého, E., Midgley, G. and Guillot, J. (1996) The Genus Malassezia with Description of Four New Species. Antonie van Leeuwenhoek, 69, 337-355. https://doi.org/10.1007/BF00399623

[41] Coutinho, S. and Paula, C. (2000) Proteinase, Phospholipase, Hyaluronidase and Chondroitin-Sulphatase Production by Malassezia pachydermatis. Medical Mycology, 38, 73-76. https://doi.org/10.1080/mmy.38.1.73.76

[42] Gemmer, C., DeAngelis, Y., Theelen, B., Boekhout, T. and Dawson, T. (2002) Fast, Noninvasive Method for Molecular Detection and Differentiation of Malassezia Yeast Species on Human Skin and Application of the Method to Dandruff Microbiology. Dournal of Clinical Microbiology, 40, 3350-3357. https://doi.org/10.1128/JCM.40.9.3350-3357.2002

[43] Gaitanis, G., Velegraki, A., Frangoulis, E., Mitroussia, A., Tsigonia, A., Tzimogianni, A., Katsambas, A. and Legakis, N. (2002) Identification of Malassezia Species from Patient Skin Scales by PCR-RFLP. Clinical Microbiology and Infection, 8, 162-173. https://doi.org/10.1046/j.1469-0691.2002.00383.x

[44] Edgar, R. (2004) MUSCLE: Multiple Sequence Alignment with High Accuracy and High Throughput. Nucleic Acids Research, 32, 1792-1797. https://doi.org/10.1093/nar/gkh340

[45] Castresana, J. (2000) Selection of Conserved Blocks from Multiple Alignments for Their Use in Phylogenetic Analysis. Molecular Biology and Evolution, 17, 540-552. https://doi.org/10.1093/oxfordjournals.molbev.a026334

[46] Tamura, K., Stecher, G., Peterson, D., Filipski, A. and Kumar, S. (2013) MEGA6: Molecular Evolutionary Genetics Analysis. Molecular Biology and Evolution, 30, 2725-2729. https://doi.org/10.1093/molbev/mst197

[47] Letunic, I. and Bork, P. (2016) Interactive Tree of Life (iTOL) v3: An Online Tool for the Display and Annotation of Phylogenetic and Other Trees. Nucleic Acids Research, 44, W242-W245. https://doi.org/10.1093/nar/gkw290

[48] Scott, D., Miller, W. and Griffin, C. (2002) Dermatología en pequeños animales. Editorial Inter-Médica, Buenos Aires.

[49] Nardoni, S., Dini, M., Taccini, F. and Mancianti, F. (2007) Ocurrence, Distribution and Population Size of Malassezia pachydermatis on Skin and Mucosae of Atopic Dog. Veterinary Microbiology, 122, 172-177. 
https://doi.org/10.1016/j.vetmic.2006.12.023

[50] Greene, C. (2008) Enfermedades infecciosas del perro y el gato. Editorial Inter-Médica, Buenos Aires.

[51] Sihelská, Z., Vaczi, P. and Conkova, E. (2016) Species Composition of Malassezia Yeasts in Dogs in Slovakia. Berliner Und Munchener Tierarztliche Wochenschrift, 129, 351-354.

[52] Buommino, E., Nocera, F., Parisi, A., Rizzo, A., Donnarumma, G., Mallardo, K., Fiorito, F., Baroni, A. and De Martino, L. (2016) Correlation between Genetic Variability and Virulence Factors in Clinical Strains of Malassezia pachydermatis of Animal Origin. New Microbiologica, 39, 216-223.

[53] Miller, W., Griffin, C. and Campbell, K. (2014) Dermatología en pequeños animales. Editorial Inter-Médica, Buenos Aires.

[54] Almeida, M., Santos, S., Mota, A., Da Silva, L., Silva, L. and Mota, R. (2016) Microbiological Isolation from the Ear of Healthy Dogs and with Otitis Externa in the Metropolitan Region of Recife, Pernambuco. Pesquisa Veterinária Brasileira, 36, 29-32. https://doi.org/10.1590/S0100-736X2016000100005

[55] Machado, M., Ferreiro, L., Ferreira, R., Corbellini, L., Deville, M., Berthelemy, M. and Guillot, J. (2011) Malassezia Dermatitis in Dogs in Brazil: Diagnosis, Evaluation of Clinical Signs and Molecular Identification. Veterinary Dermatology, 22, 46-52. https://doi.org/10.1111/j.1365-3164.2010.00909.x

[56] Somerville, D. (1971) Colonisation by Pityrosporum pachydermatis. The Lancet, 297, 799. https://doi.org/10.1016/S0140-6736(71)91237-2

[57] Gordon, M. (1979) Malassezia Pityrosporum pachydermatis (Weidman) Dodge 1935. Sabouraudia, 17, 305-309. https://doi.org/10.1080/00362177985380451

[58] Guého, E., Simmons, R., Pruitt, W., Meyer, S. and Ahearn, D. (1987) Association of Malassezia pachydermatis with Systemic Infections of Humans. Journal of Clinical Microbiology, 25, 1789-1790.

[59] Bandhaya, M. (1993) The Distribution of Malassezia furfur and Malassezia pachydermatis on Normal Human Skin. The Southeast Asian Journal of Tropical Medicine and Public Health, 24, 343-346.

[60] Bernier, V., Weill, F., Hirigoyen, V., Elleau, C., Feyler, A., Labrèze, C., Sarlangue, J., Chène, G., Couprie, B. and Taïeb, A. (2002) Skin Colonization by Malassezia Species in Neonates: A Prospective Study and Relationship with Neonatal Cephalic Pustulosis. Archives of Dermatology, 138, 215-218. https://doi.org/10.1001/archderm.138.2.215

[61] Nakabayashi, A., Sei, Y. and Guillot, J. (2000) Identification of Malassezia Species Isolated from Patients with Seborrhoeic Dermatitis, Atopic Dermatitis, Pityriasis Versicolor and Normal Subjects. Medical Mycology, 38, 337-341. https://doi.org/10.1080/mmy.38.5.337.341

[62] Giusiano, G., Sosa, M., Rojas, F., Vanacore, S. and Mangiaterra, M. (2010) Prevalence of Malassezia Species in Pityriasis Versicolor Lesions in Northeast Argentina. Revista Iberoamericana de Micología, 27, 71-74. https://doi.org/10.1016/j.riam.2009.12.005

[63] Sosa, M., Rojas, F., Mangiaterra, M. and Giusiano, G. (2013) Prevalencia de especies de Malassezia asociadas a lesiones de dermatitis seborreica en pacientes de Argentina. Revista Iberoamericana de Micología, 30, 239-242. https://doi.org/10.1016/j.riam.2013.02.002

[64] Kaur, M., Narang, T., Bala, M., Gupte, S., Aggarwal, P. and Manhas, A. (2013) Study 
of the Distribution of Malassezia Species in Patients with Pityriasis Versicolor and Healthy Individuals in Tertiary Care Hospital, Punjab. Indian Journal of Medical Microbiology, 31, 270-274. https://doi.org/10.4103/0255-0857.115636

[65] Larocco, M., Dorenbaum, A., Robinson, A. and Pickering, L. (1988) Recovery of Malassezia pachydermatis from Eight Infants in a Neonatal Intensive Care Nursery: Clinical and Laboratory Features. The Pediatric Infectious Disease Journal, 7, 398-401. https://doi.org/10.1097/00006454-198806000-00006

[66] Mickelsen, P., Viano, M., Stevens, D. and Díaz, P. (1988) Clinical and Microbiological Features of Infection with Malassezia pachydermatis in High-Risk Infants. The Journal of Infectious Diseases, 157, 1163-1168. https://doi.org/10.1093/infdis/157.6.1163

[67] Van Belkum, A., Boekhout, T. and Bosboom, R. (1994) Monitoring Spread of Malassezia Infections in a Neonatal Intensive Care Unit by PCR-Mediated Genetic Typing. Journal of Clinical Microbiology, 32, 2528-2532.

[68] Chryssanthou, E., Broberger, U. and Petrini, B. (2001) Malassezia pachydermatis Fungaemia in a Neonatal Intensive Care Unit. Acta Paediatrica, 90, 323-327. https://doi.org/10.1080/080352501300067712

[69] Welbel, S., McNeil, M., Pramanik, A., Silberman, R., Oberle, A., Midgley, G., Crow, S. and Jarvis, W. (1994) Nosocomial Malassezia pachydermatis Bloodstream Infections in a Neonatal Intensive Care Unit. The Pediatric Infectious Disease Journal, 13, 104-108. https://doi.org/10.1097/00006454-199402000-00005

[70] Marcus, L. and Marcus, E. (1998) Nosocomial Zoonoses. The New England Journal of Medicine, 338, 757-759. https://doi.org/10.1056/NEJM199803123381110

[71] Sugita, T., Boekhout, T., Velegraki, A., Guillot, J., Hadina, S. and Cabañes, J. (2010) Epidemiology of Malassezia-Related Skin Diseases. In: Boekhout, T., Guého, E., Mayser, P. and Velegraki, A., Ed., Malassezia and the Skin, Springer-Verlag, Berlin, 65-119. https://doi.org/10.1007/978-3-642-03616-3_3

[72] Cabañes, F., Hernández, J. and Castellá, G. (2005) Molecular Analysis of Malassezia sympodialis-Related Strains from Domestic Animals. Journal of Clinical Microbiology, 43, 277-283. https://doi.org/10.1128/JCM.43.1.277-283.2005

[73] Cafarchia, C., Gasser, R., Latrofa, M., Parisi, A., Campbell, B. and Otranto, D. (2008) Genetic Variants of Malassezia pachydermatis from Canine Skin: Body Distribution and Phospholipase Activity. FEMS Yeast Research, 8, 451-459.

https://doi.org/10.1111/j.1567-1364.2008.00358.x 